\title{
ALFABETIZADORAS DE OURO PRETO-MG E SUAS CONCEPÇÕES DE ALFABETIZAÇÃO E \\ LETRAMENTO A PARTIR DO PNAIC
}

Regina Aparecida Correa ${ }^{* *}$
Hércules Tolêdo Corrêa ${ }^{* * *}$

\section{Resumo}

Este artigo teve como objetivo geral analisar as concepções acerca dos processos de alfabetização e letramento de cinco professoras alfabetizadoras do município de Ouro Preto - MG, as quais participaram da formação continuada no âmbito do Pacto Nacional pela Alfabetização na Idade Certa - PNAIC, em 2013. De abordagem qualitativa, a investigação utilizou como instrumentos de coleta de dados o questionário e a entrevista semiestruturada. Os dados apontam que a unidade do PNAIC relacionada ao sistema de escrita alfabética e à consciência fonológica foi a que mais marcou as professoras e que houve certa dificuldade por parte delas em conceituar letramento e em descrever atividades em que este tenha sido trabalhado.

Palavras-chave: Concepções de alfabetização e letramento. Formação continuada de professoras alfabetizadoras. Pacto Nacional pela Alfabetização na Idade Certa - PNAIC.

\section{Introdução}

O presente artigo é um recorte de uma pesquisa de mestrado realizada no Programa de PósGraduação, Mestrado em Educação, da Universidade Federal de Ouro Preto - UFOP. Teve como objetivo geral analisar as concepções acerca dos processos de alfabetização e letramento de cinco professoras alfabetizadoras do município de Ouro Preto - MG, as quais participaram da formação continuada no âmbito do Pacto Nacional pela Alfabetização na Idade Certa - PNAIC, em 2013, em seu município.

O PNAIC é um compromisso assumido entre o governo federal, os estados e municípios, instituído pela Portaria no 867, em 4 de julho de 2012, a fim de alfabetizar as crianças até no máximo oito anos de idade, ao final do 3 o ano do Ensino Fundamental, avaliando-se os resultados por meio de exame periódico específico. Está organizado em quatro eixos: Formação Continuada de Professores Alfabetizadores; Materiais Didáticos, Literatura e Tecnologias Educacionais; Avaliação e; Gestão, Controle e Mobilização Social.

\footnotetext{
** Mestra em Educação pela UFOP - Universidade Federal de Ouro Preto. Contato: reginacorreasol@hotmail.com

*** Doutor em Educação pela UFMG - Universidade Federal de Minas Gerais, Professor da UFOP - Universidade Federal de Ouro Preto. Contato: herculest@cead.ufop.br
} 
Para esta pesquisa foram selecionadas cinco professoras alfabetizadoras, tendo em vista os seguintes critérios: ter participado de toda a formação no âmbito do PNAIC, voltada para a Língua Portuguesa, no ano de 2013 e; ter trabalhado em turmas de 10 ano do Ensino Fundamental nos anos de 2013, 2014, 2015 e 2016.

A estas professoras foram aplicados dois questionários e realizadas duas entrevistas abordando, especialmente, questões relacionadas aos temas discutidos ao longo da formação no âmbito do PNAIC. A partir dos dados obtidos elaboramos duas categorias de análise de dados: 1) 0 Sistema de Escrita Alfabética - SEA e a Consciência Fonológica e 2) Concepções de Alfabetização e Letramento. Por meio destas categorias foi possível obter indícios das concepções de alfabetização e letramento das professoras participantes da pesquisa.

Dessa forma, na primeira seção deste artigo fazemos algumas breves considerações acerca dos conceitos de alfabetização e letramento. Na segunda, explicitamos a metodologia utilizada na pesquisa. Por fim, na terceira seção, apresentamos a análise dos dados coletados.

\section{Brevíssimas considerações teóricas sobre alfabetização e letramento}

A história da alfabetização escolar no Brasil é marcada por sucessivas mudanças conceituais e consequentemente metodológicas, sendo o fracasso da escola em conduzir os educandos ao domínio da língua escrita o grande propulsor de modificações na alfabetização (SOARES, 2004, 2016). Até por volta dos anos 1980, enfatizava-se a aprendizagem do sistema convencional da escrita. Assim, as discussões giravam em torno dos métodos de alfabetização. No entanto, tendo ocupado o centro das discussões acerca da alfabetização por quase um século, os métodos tradicionais sofreram um "desinvestimento" por volta de 1980, uma vez que outros temas ganharam destaque mediante a divulgação de alguns estudos, como os relacionados ao letramento e à teoria da psicogênese da língua escrita, no Brasil (MORAIS, 2006).

Com relação aos estudos referentes aos fatores psicogenéticos da aprendizagem da língua escrita, por meio do livro Psicogênese da Língua Escrita, Ferreiro e Teberosky (1986) buscaram demonstrar que, por trás dos métodos e manuais de alfabetização, existe um sujeito que adquire conhecimentos de maneira ativa, criando hipóteses para tal, e que, muitas vezes, são ignoradas pela escola ou consideradas como deficiências e/ou dificuldades de aprendizagem.

No que concerne aos estudos referentes ao letramento, Soares (2004) aponta que estes surgiram ao mesmo tempo em sociedades distanciadas geográfica, social, econômica e culturalmente como Portugal, Inglaterra, Estados Unidos e França, a partir da necessidade de reconhecer e nomear práticas de leitura e de escrita mais complexas que aquelas decorrentes da aprendizagem do sistema de escrita, numa faceta mais social e antropológica dos estudos. 
Apesar das diversas contribuições que tanto os estudos relacionados à psicogênese da língua escrita quanto os referentes ao letramento trouxeram para a reflexão e compreensão do processo de ensino e aprendizagem da leitura e da escrita no Brasil, em determinados contextos, estes conceitos foram mal interpretados, o que acabou fazendo com que a alfabetização perdesse, muitas vezes a sua especificidade, o que Soares (2004) chamou de "desinvenção da alfabetização".

Com relação à alfabetização e ao letramento, um dos caminhos propostos para a superação da dicotomia entre estes termos seria o que alguns autores, como a própria Magda Soares (2004, p. 5), têm chamado de "alfabetizar letrando" ou "letrar alfabetizando".

Assim, letrar alfabetizando ou alfabetizar letrando seria uma possibilidade de garantir aos alunos a aprendizagem do sistema alfabético e ortográfico da língua escrita ao mesmo tempo em que ocorreria a inserção destes nas práticas sociais da cultura escrita.

Neste contexto, esta pesquisa pretendeu analisar concepções acerca dos processos de alfabetização e letramento de cinco professoras alfabetizadoras do município de Ouro Preto - MG, que participaram do PNAIC, em 2013.

\section{Metodologia}

Esta pesquisa, de abordagem qualitativa, foi realizada utilizando-se como instrumentos de coleta de dados o questionário e a entrevista semiestruturada. Para a realização deste trabalho foram selecionadas cinco professoras alfabetizadoras do município de Ouro Preto-MG, considerando-se os seguintes critérios: ter participado de toda a formação no âmbito do PNAIC, voltada para a Língua Portuguesa, no ano de 2013; e ter trabalhado em turmas de 10 ano do Ensino Fundamental nos anos de 2013, 2014, 2015 e 2016.

É importante explicitar que a formação ministrada em 2013, no âmbito do eixo de Formação Continuada dos Professores Alfabetizadores, foi organizada em oito unidades para cada ano do Ciclo de Alfabetização (1으, 2o e 3ํ), totalizando oitenta horas, mais o seminário de encerramento, com carga horária de oito horas. Essas unidades foram trabalhadas durante dez meses e as referentes ao 10 ano do Ensino Fundamental abordaram os seguintes temas: Concepções de alfabetização, currículo, interdisciplinaridade e inclusão; Planejamento escolar, materiais e recursos didáticos (PNBE, PNBE Especial, PNLD e jogos); Sistema de Escrita Alfabética e consciência fonológica; Ambientes de alfabetização, jogos e brincadeiras, inclusão e literatura; Diferentes gêneros textuais na alfabetização; Projetos didáticos, sequências didáticas e interdisciplinaridade; Inclusão e alfabetização; Processos de avaliação.

Por meio da aplicação do questionário e da entrevista as professoras explicitaram os temas que consideraram mais e menos relevantes ao longo da formação, e mencionaram aspectos 
significativos que dão indícios das concepções de alfabetização e letramento das professoras participantes da pesquisa.

As entrevistas foram gravadas em áudio e posteriormente transcritas, computando-se um total de 3 horas, 42 minutos e 15 segundos de gravação e 74 páginas de transcrição.

\section{Análise de dados: as concepções das alfabetizadoras}

Nesta seção, apresentamos os dados relacionados às professoras alfabetizadoras participantes da pesquisa. Esses dados foram coletados por meio da aplicação de dois questionários e da realização de duas entrevistas semiestruturadas com cada uma das docentes.

O primeiro questionário abordou questões relacionadas à: idade, formação acadêmica/profissional, trajetória profissional, motivação para participação no PNAIC, avaliação dos temas abordados durante a formação de professores no âmbito do Pacto, avaliação do trabalho desenvolvido pelas orientadoras de estudos e autoavaliação da participação das professoras na formação continuada. Por meio dessas questões, foi possível levantar o perfil das professoras alfabetizadoras, conforme pode ser observado no quadro 1. É importante destacarmos que, por uma questão ética, o nome das professoras não será mencionado, sendo utilizado um pseudônimo, escolhido por elas, todas as vezes que a elas nos referirmos neste artigo.

Quadro 1 - Perfil das professoras participantes da pesquisa

\begin{tabular}{|c|c|c|c|c|}
\hline Professoras & Idade & Graduação & Especialização & $\begin{array}{c}\text { Tempo de } \\
\text { atuação }\end{array}$ \\
\hline Ana & 38 anos & $\begin{array}{c}\text { Educação Básica - Anos } \\
\text { Iniciais }\end{array}$ & $\begin{array}{c}\text { Alfabetização e } \\
\text { Letramento }\end{array}$ & 15 anos \\
\hline Juliana & 43 anos & Magistério Superior & - & 20 anos \\
\hline Malu & 49 anos & Curso Superior Normal & - & 20 anos \\
\hline Mariana & 50 anos & Letras e Normal Superior & Ensino da Língua & Portuguesa \\
\hline Olívia & 39 anos & Normal Superior & Psicopedagogia & 20 anos \\
\hline
\end{tabular}

Fonte: Elaborado pelos autores.

Por meio do questionário aplicado foi possível perceber que as professoras alfabetizadoras possuem entre trinta e oito e cinquenta anos, todas fizeram graduação e três possuem especialização. Três delas têm em torno de 20 anos de experiência, uma possui 15 e a outra possui 
13. Assim, nota-se que todas possuem experiência com a docência nos Anos Iniciais do Ensino Fundamental.

$\mathrm{Na}$ primeira entrevista, conforme pode ser observado no quadro abaixo, foi possível constatar que, entre os temas trabalhados, os que foram considerados pelas professoras como os mais relevantes foram: Heterogeneidade na alfabetização, Projetos Didáticos e Sequências Didáticas, Gêneros Textuais, Ludicidade e Planejamento Escolar; e como temas menos importantes: Currículo na Alfabetização, Avaliação, Projetos Didáticos e Sequências Didáticas, e Sistema de Escrita Alfabética. Duas professoras consideraram a avaliação como o tema menos importante.

Quadro 2 - Temas mais e menos relevantes apontados no 1 q questionário

\begin{tabular}{|l|l|l|}
\hline \multicolumn{2}{|c|}{1 Q Questionário } \\
\hline Professora & \multicolumn{1}{|c|}{ Tema mais importante } & Tema menos importante \\
\hline Ana & Gêneros textuais & Avaliação \\
\hline Juliana & Planejamento escolar & Avaliação \\
\hline Malu & Planejamento Escolar & Sistema de escrita alfabética \\
\hline Mariana & Ludicidade e Projetos didáticos e & Currículo na alfabetização \\
\hline Olívia & sequências didáticas & Projetos didáticos e sequências \\
& Heterogeneidade na alfabetização & didáticas \\
\hline
\end{tabular}

Fonte: Elaborado pelos autores.

É importante destacarmos que, nas duas questões referentes ao tema mais e menos relevante, foram utilizadas algumas palavras-chave para representar cada um dos temas trabalhados. Desse modo, as palavras-chave que corresponderam aos temas do 1 ao 8 na primeira entrevista foram, respectivamente: Currículo na alfabetização, Planejamento Escolar, Sistema de Escrita Alfabética, Ludicidade, Gêneros Textuais, Projetos Didáticos e Sequências Didáticas, Heterogeneidade na alfabetização e Avaliação.

Os dados coletados por meio do primeiro questionário e da primeira entrevista possibilitaram conhecer as professoras alfabetizadoras e ter uma visão panorâmica sobre as implicações da sua participação no PNAIC. No entanto, considerando o objetivo geral desta pesquisa, percebeu-se a necessidade de um novo contato com as professoras para refinamento dos dados coletados. 
Aprofundar questões relacionadas aos temas trabalhados na formação poderia nos dar indícios das concepções de alfabetização e letramento das professoras alfabetizadoras participantes da formação que ocorreu no âmbito do PNAIC em 2013. Além disso, percebemos que, ao responder às questões relacionadas aos temas mais e menos relevantes, do primeiro questionário, as professoras ficaram com recordações um pouco vagas sobre os temas abordados no curso, uma vez que a formação ocorreu em 2013, de modo que a elaboração de uma nova questão, com a inserção da ementa com os temas discutidos em cada uma das unidades, e a inclusão de palavras-chave que explicitassem melhor cada um dos cadernos poderiam trazer novos dados para a pesquisa.

Assim, elaboramos uma nova questão, com a inserção da ementa e a inclusão de novas palavras-chave, e solicitamos às professoras que ordenassem as unidades trabalhadas de 1 a 8 , em que o número 1 seria o tema mais relevante e o 8 o menos.

No quadro abaixo, é possível observar os temas apontados pelas professoras como mais e menos relevantes no segundo questionário:

Quadro 3 - Temas mais e menos relevantes apontados no 2o questionário

\begin{tabular}{|c|c|c|}
\hline \multicolumn{3}{|c|}{ 20 Questionário } \\
\hline Professoras & Temas mais relevantes & Temas menos relevantes \\
\hline Ana & $\begin{array}{l}\text { 1. Ambientes de alfabetização, jogos e } \\
\text { brincadeiras, inclusão e literatura; } \\
\text { 2. Planejamento Escolar, materiais e } \\
\text { recursos didáticos (PNBE, PNBE } \\
\text { Especial, PNLD e jogos). }\end{array}$ & $\begin{array}{l}\text { 8. Processos de avaliação; } \\
\text { 7. Projetos Didáticos, sequências } \\
\text { didáticas, interdisciplinaridade. }\end{array}$ \\
\hline Juliana & $\begin{array}{l}\text { 1. Inclusão e alfabetização; } \\
\text { 2. Processos de avaliação. }\end{array}$ & $\begin{array}{l}\text { 8. Planejamento escolar, materiais e } \\
\text { recursos didáticos (PNBE, PNBE } \\
\text { Especial, PNLD e jogos); } \\
\text { 7. Concepções de alfabetização, } \\
\text { currículo, interdisciplinaridade e } \\
\text { inclusão. }\end{array}$ \\
\hline Malu & $\begin{array}{l}\text { 1. Sistema de escrita alfabética e } \\
\text { consciência fonológica; } \\
\text { 2. Planejamento Escolar, materiais e } \\
\text { recursos didáticos (PNBE, PNBE } \\
\text { Especial, PNLD e jogos). }\end{array}$ & $\begin{array}{l}\text { 8. Processos de avaliação; } \\
\text { 7. Diferentes gêneros textuais na } \\
\text { alfabetização. }\end{array}$ \\
\hline Mariana & $\begin{array}{l}\text { 1. Sistema de escrita alfabética e } \\
\text { consciência fonológica; } \\
\text { 2. Ambientes de alfabetização, jogos e }\end{array}$ & $\begin{array}{l}\text { 8. Planejamento escolar, materiais e } \\
\text { recursos didáticos (PNBE, PNBE } \\
\text { Especial, PNLD e jogos); }\end{array}$ \\
\hline
\end{tabular}




\begin{tabular}{|c|c|c|c|}
\hline & & brincadeiras, inclusão e literatura. & 7. Processos de avaliação. \\
\hline Olívia & 1. & $\begin{array}{l}\text { Concepções de Alfabetização, } \\
\text { currículo, interdisciplinaridade e } \\
\text { inclusão; } \\
\text { Sistema de Escrita Alfabética e } \\
\text { consciência fonológica. }\end{array}$ & $\begin{array}{l}\text { 8. Projetos Didáticos, sequências } \\
\text { didáticas, interdisciplinaridade; } \\
\text { 7. Processos de Avaliação. }\end{array}$ \\
\hline
\end{tabular}

Fonte: Elaborado pelos autores.

Ao analisar os dados expostos no quadro acima, foi possível perceber que houve uma alteração significativa em relação aos resultados apresentados no primeiro questionário. Verificamos modificações em todas as respostas, com exceção da Profa. Malu, que apontou Planejamento Escolar como o tema mais importante no primeiro questionário e apontou-o como o segundo mais relevante no segundo.

Com relação aos temas assinalados como menos relevantes, observamos também que houve modificações nas respostas das professoras, com exceção das docentes Ana e Olívia, considerando que, nos dois questionários, a primeira marcou o caderno relacionado à Avaliação como o menos relevante, e a segunda marcou o caderno relacionado a Projetos Didáticos, Sequências Didáticas e Interdisciplinaridade como o menos relevante nos dois questionários.

Hipotetiza-se que essa alteração nas respostas se deve a dois fatores: primeiro, porque a inclusão da ementa possibilitou às professoras se recordarem melhor dos temas abordados na formação, o que gerou respostas mais concretas e consistentes do que as dadas no primeiro questionário e entrevista. Segundo, porque, de acordo com Amado e Ferreira (2014), o entrevistado vai adquirindo confiança no entrevistador, e isso pode fazer com que as respostas dadas pelo sujeito sejam menos superficiais e estereotipadas, e até mesmo contraditórias, com relação às respostas iniciais.

A partir das respostas assinaladas no questionário, realizamos a segunda entrevista com as professoras alfabetizadoras no intuito de verificar as razões que as haviam levado a marcar um ou outro tema como o mais ou menos relevante e compreender o que os seus depoimentos revelavam sobre suas concepções de alfabetização e letramento. A partir daí, elencamos duas categorias de análise dos dados: 1) o Sistema de Escrita Alfabética - SEA e a Consciência Fonológica e 2) Concepções de Alfabetização e Letramento. 


\subsection{O Sistema de Escrita Alfabética - SEA e a Consciência Fonológica na voz das professoras alfabetizadoras}

O Sistema de Escrita Alfabética-SEA e a Consciência Fonológica foram temas abordados na terceira unidade do curso de formação continuada com os seguintes objetivos: entender a concepção de alfabetização na perspectiva do letramento, compreendendo que o processo de aprendizagem da escrita alfabética consiste não na aquisição de um código, mas na compreensão de um sistema notacional; analisar as contribuições da psicogênese da língua escrita para a compreensão do processo de aprendizagem do SEA; entender as relações entre alfabetização e consciência fonológica; e analisar alternativas didáticas para o ensino do SEA (BRASIL, 2012).

O tema Sistema de Escrita Alfabética e Consciência Fonológica foi apontado como um dos mais relevantes por três professoras e citado pelas outras duas.

Ana, ao falar desse tema, disse que não conhecia a expressão Consciência Fonológica antes de sua participação no PNAIC, mas que, quando esse conceito foi explicado, viu que já desenvolvia atividades relacionadas a ele em sua sala de aula sem que tivesse a percepção do que estava fazendo.

A docente definiu consciência fonológica relacionando esse conceito com os seus conhecimentos práticos, pontuando que consciência fonológica é a criança perceber as partes da palavra, verificando que a palavra tem início, meio e fim; relacionar a primeira letra de uma palavra com os nomes dos colegas; a sílaba mediana, que até então não era trabalhada; identificar que a vogal sozinha pode formar uma sílaba e a consoante não; e que uma sílaba pode ter apenas uma letra, mas pode ter outras.

É possível perceber que a professora menciona diversos aspectos relacionados às propriedades do SEA, como a questão da variação quanto às combinações entre consoantes, vogais e semivogais; a presença da vogal em todas as sílabas do português; e a notação da pauta sonora pelas letras.

A terceira unidade dos cadernos de formação, referente ao SEA e à consciência fonológica, pontua que, desde a década de 1970, diversas pesquisas têm apontado uma relação entre a consciência fonológica e a aquisição da escrita alfabética. Além disso, essa unidade define consciência fonológica como um grande conjunto de habilidades que permitem refletir sobre as partes sonoras das palavras (BRASIL, 2012).

Morais (2012) defende que é necessário auxiliar as crianças a descobrirem as propriedades ou regras do SEA desde cedo e a consciência fonológica exerceria um importante papel nesse processo. 
A professora mencionou que uma das atividades que ela utiliza para avaliar a escrita dos alunos é a escrita espontânea. Perguntamos a ela se já realizava essa atividade antes do PNAIC e com que frequência ela utilizava isso em sala de aula. Ana respondeu que já realizava essa atividade antes de participar do curso, mas que pode ver outras formas de trabalhar a atividade. Com relação à frequência com que realiza essa atividade, disse que, no início do ano, sempre faz uma avaliação diagnóstica para saber como os alunos estão e costuma dar esta mesma atividade no meio do ano. Disse que não trabalha com isso toda semana, mas de quinze em quinze dias, de mês em mês; e que, a partir do segundo semestre, inclui novas palavras, com um grau maior de dificuldades, considerando que os alunos já estão num nível mais avançado da alfabetização.

Ao perguntar à professora se ela fazia o acompanhamento dos níveis de conceitualização da escrita dos educandos ao longo do ano, ela relatou uma dificuldade que ela e algumas colegas haviam vivido quando a formação no âmbito do PNAIC foi retomada em 2016. De acordo com a docente, um dos trabalhos que necessitava ser feito, no primeiro encontro, era separar algumas atividades por níveis. Assim, seu grupo teria ficado responsável por selecionar atividades para o nível pré-silábico. No entanto, teriam selecionado atividades para o nível silábico.

Assim, Ana conclui alegando que as orientadoras de estudos disseram que iriam focar mais nesse conteúdo "pra gente poder também ter mais esclarecimento, porque a gente sabe que existem os níveis, mas na hora de encaixar a criança naquele nível, entendeu? Até a gente tem um pouco de dificuldade também". (ANA)

A Profa. Juliana, ao falar das caixas de jogos, relatou a sua importância para trabalhar com a sílaba inicial, som e letra inicial, ou seja, com o SEA.

Ao descrever seu trabalho com alfabetização, Juliana mencionou que havia entrado na página do Alfaletrar, projeto desenvolvido por Magda Soares junto à Secretaria de Educação do município de Lagoa Santa-MG. Um pouco mais adiante, disse que leu no site que a alfabetização e o letramento devem caminhar juntos e deu alguns exemplos de como trabalha com a alfabetização na perspectiva do letramento, afirmando trabalhar muito com textos, histórias, mas também com jogos e atividades orais, focando em atividades que levem os alunos a refletirem sobre as palavras e suas propriedades.

Ainda sobre a plataforma do Alfaletrar, a docente afirmou que "mostra também os níveis de cada aluno, em que eles estão: silábico, pré-silábico, o que você deve fazer pra poder tá fazendo pra que eles tenham uma consciência, a consciência fonológica, da palavra, tudo assim, nó, muito bom." (JULIANA)

A recorrência com que a professora falava do projeto desenvolvido em Lagoa Santa nos chamou a atenção, pois se referia a ele para mencionar temas que haviam sido abordados no PNAIC. Nossa hipótese é a de que, talvez pelo fato de a formação no projeto ser desenvolvida junto às 
professoras, compreendendo e dialogando com as suas necessidades, a plataforma tenha conseguido esclarecer questões mais próximas da realidade da docente do que o PNAIC, em virtude de ser um programa de âmbito nacional, o que dificulta pensar nas particularidades de cada região.

Ao falar dos níveis de conceitualização da escrita e das intervenções que o professor pode fazer para que as crianças evoluam, descritas na página do Alfaletrar, a docente parece revelar uma dificuldade/dúvida que tinha até então em relação a esses aspectos, como também citada anteriormente pela Profa. Ana, que pode ter sido sanada/esclarecida pelas informações constantes na plataforma.

Como atividades para avaliar os níveis de conceitualização da escrita, a educadora afirma utilizar a escrita espontânea, jogos e ditados, ressaltando que, embora este último seja considerado algo do passado, gosta muito de trabalhar com ele, pois, em sua sala de aula, ele dá resultado, destacando que o aluno ouve a palavra para depois registrá-la.

A Profa. Malu disse que com o PNAIC foi possível conhecer os níveis de conceitualização da escrita detalhadamente, uma vez que "a princípio a gente não tinha essa noção de que às vezes o menino tava no silábico, mas não sabia se ele tava no silábico sem valor sonoro ou com valor não sonoro. Agora a gente sabe tudo direitinho cada um deles." (MALU) A professora complementou dizendo que "o silábico é dividido em dois, e antes não falava. Falava só de um, entendeu?". (MALU) Afirmou que, como atividades para avaliar a escrita dos alunos, trabalha com jogos de sílabas, jogos de letras para montar "palavrinhas" e com desenhos.

A alfabetizadora Mariana argumentou que, para a apropriação do SEA, é fundamental que a criança perceba os sons e que a consciência fonológica é fundamental para isso. A professora afirmou que, antes do PNAIC, não conhecia a consciência fonológica e a conceituou acenando para a relação existente entre aos sons e a representação gráfica.

A fala de Mariana vem ao encontro do que Soares (2016) afirma em seu livro mais recente, de que, para compreender a escrita alfabética, é preciso direcionar a atenção para o estrato fônico das palavras, definindo consciência fonológica como a capacidade de focar os sons das palavras, distinguindo-os de seu significado, e segmentá-las nos sons que a constituem.

A esse respeito, é importante mencionar que, para Morais (2012), se a consciência fonológica não é suficiente para que uma criança se torne alfabetizada, algumas habilidades dela são fundamentais para que os educandos avancem nas suas hipóteses sobre o SEA.

Mariana parece dominar os conhecimentos acerca dos níveis de conceitualização da escrita ao descrever que, no início do ano, a maioria dos seus alunos estava no nível pré-silábico, dizendo que sabiam que eram usadas letras para escrever, mas não tinham ainda a percepção do valor sonoro. A professora relatou algumas atividades dadas a fim de que os educandos pudessem evoluir 
na escrita, entre elas, atividades voltadas para a percepção da letra e o som inicial, som final, som das vogais e consoantes, e rimas.

A docente afirmou acompanhar a evolução da conceitualização dos níveis de escrita por meio da escrita espontânea, dada geralmente uma vez ao mês. Com relação às atividades de intervenção, a professora afirmou trabalhar com os jogos da caixa do PNAIC e com outros que ela confecciona ou encontra, como o alfabeto móvel, a sílaba móvel e jogos de encaixe.

Quando perguntei à professora como era o seu trabalho com o SEA e a consciência fonológica antes do PNAIC, ela disse que, em termos de alfabetização, não saberia dizer, pois, até então, trabalhava com turmas de alunos mais velhos, mas que acreditava que seria mais pobre e não fluiria tanto: "Eu nunca tinha trabalhado com alfabetização antes. Então eu não sei, pra mim o PNAIC foi um aprendizado. Me ensinou a trabalhar com alfabetização." (MARIANA)

Ao conversarmos sobre o Sistema de Escrita Alfabética e a Consciência Fonológica, tema que a professora elegeu como o segundo mais relevante, Olívia disse que não tinha ouvido falar sobre a consciência fonológica antes da sua participação no PNAIC.

Com relação aos níveis de conceitualização da escrita, a docente afirmou que já os conhecia desde que se formou e demonstrou certo domínio em identificá-los ao afirmar, sobre o desenvolvimento dos seus alunos, que "estão todos, assim, só tirando uma menina, alfabéticos. Os outros seis estão alfabéticos", e mais adiante, ao responder em que nível estava a referida aluna, descreveu que "ela tá no pré-silábico, ela usa qualquer letra pra qualquer coisa. Com som nem nada." (OLÍVIA)

Por meio do exposto até este ponto, é possível perceber que três professoras (Ana, Mariana e Olívia) apontaram o conceito de "consciência fonológica" como um conceito novo, afirmando não ter ouvido falar deste conceito antes do PNAIC, embora desenvolvessem algumas atividades relacionadas à consciência fonológica. Esse dado é importante, pois aponta que o programa de formação continuada fez com que as professoras pudessem compreender teoricamente algo que já desenvolviam na prática.

Com relação à compreensão teórica dos aspectos desenvolvidos na prática destacamos que conhecer os conceitos embutidos no processo de ensino e aprendizagem da leitura e da escrita é fundamental para o desenvolvimento de um bom trabalho.

No que concerne aos níveis de conceitualização da escrita, foi possível perceber que os conteúdos abordados neste caderno contribuíram para a formação das docentes, embora uma delas tenha relatado um pouco de dificuldade em relação a esses. No entanto, verificamos que a maior parte das docentes encontrou certa dificuldade em descrever as atividades de intervenção que fazem para que os discentes evoluam em seus níveis de conceitualização da escrita. Nesse sentido, é fundamental destacar que, se é importante identificar em que nível de conceitualização da escrita os 
alunos estão, isso não é suficiente. É necessário promover situações em que os discentes possam evoluir em suas hipóteses.

\subsection{As concepções de Alfabetização e Letramento na voz das professoras alfabetizadoras}

É importante destacar que a questão da concepção de alfabetização na perspectiva do letramento permeou seis das oito unidades dos cadernos de estudos do PNAIC. Assim, com exceção das unidades 4 e 8 , todas as demais tiveram um ou mais objetivos relacionados a essa questão.

Os objetivos das unidades 1, 2, 3, 5, 6 e 7 relacionados à questão da alfabetização na perspectiva do letramento foram, respectivamente: entender a concepção de alfabetização na perspectiva do letramento; aprofundar os conhecimentos sobre a concepção de alfabetização na perspectiva do letramento e planejar o ensino na alfabetização, analisando e criando propostas de organização de rotinas da alfabetização na perspectiva do letramento; entender a concepção de alfabetização na perspectiva do letramento, compreendendo que a aprendizagem da escrita alfabética constitui um processo de compreensão de um sistema de notação e não a aquisição de um código; entender a concepção de alfabetização na perspectiva do letramento; compreender a concepção de alfabetização na perspectiva do letramento, a partir do aprofundamento de estudos baseados nas obras pedagógicas do Programa Nacional Biblioteca da Escola- PNBE do Professor e outros textos publicados pelo MEC; entender a concepção de alfabetização na perspectiva do letramento, considerando o fenômeno da heterogeneidade como intrínseco aos processos educativos e planejar o ensino na alfabetização, analisando e criando propostas de organização de rotinas da alfabetização na perspectiva do letramento, adequando-as às diferentes necessidades de aprendizagem dos alunos.

Nesta subseção, trazemos algumas reflexões sobre os depoimentos das participantes desta pesquisa que nos dão indícios das suas concepções acerca do letramento.

Ana, embora não tenha apontado o Sistema de Escrita Alfabética e Consciência Fonológica como tema mais relevante, destacou, em seu depoimento, a importância deste, especialmente no que se refere à consciência fonológica, como já explicitado anteriormente. A docente assinalou o tema Diferentes Gêneros Textuais na Alfabetização como o terceiro mais relevante, pontuando que, muitas vezes, o professor fica preso a apenas um gênero textual, ressaltando a importância de trabalhar com as características de diferentes gêneros.

Em outro momento do depoimento, a professora reiterou a questão apontada acima relativa a apenas um gênero textual, afirmando que, muitas vezes, o professor considera que os discentes são muito pequenos e que não precisam entrar em contato com outros gêneros textuais, mas que 
eles precisam saber, pois, em seu dia a dia, "o pai lê jornal, ele vai ver um jornal, ele vai ver uma propaganda na televisão." (ANA) Nesse sentido, a alfabetizadora falou da possibilidade de trabalhar com outros textos.

Aproveitando que a professora tinha falado sobre o trabalho com diferentes gêneros textuais, perguntamos a ela se trabalhava com a alfabetização na perspectiva do letramento. Ela afirmou que sim, argumentando que, anteriormente, a criança era mais desinformada, citando como exemplo que, quando seu filho era aluno, não tinha muito acesso à internet, mas que, hoje em dia, as crianças chegam à escola "totalmente letradas", enfatizando seu conhecimento prévio.

Outro aspecto interessante do depoimento de Ana é que ela não conseguiu relacionar a fala anterior, em que dizia dos diferentes gêneros textuais, com a fala seguinte, ao responder se trabalhava com a alfabetização na perspectiva do letramento.

Perguntei à Ana se poderia citar alguma atividade que ela havia dado considerando o letramento. A professora citou atividades em que trabalha "coisas da atualidade", levanta os conhecimentos prévios dos discentes, solicita a eles que exponham sua opinião e trabalha a oralidade.

Nota-se que, se antes a professora dizia da importância de trabalhar com diferentes gêneros textuais, ao pedir que desse algum exemplo de atividade que trabalhou considerando o letramento, a professora não os retoma, mencionando agora questões referentes à oralidade e aos conhecimentos prévios dos alunos.

Um aspecto que pode ser percebido é que aparece, na fala da professora, certa dificuldade/insegurança em definir o que é letramento ao dizer "O que é o letramento? Porque, às vezes, assim, pra definir, a gente tem hora que..." (ANA) e assim dá sequência ao seu depoimento. Essa dificuldade/insegurança em conceituar letramento aparece em outros dois momentos: ao perguntar para a pesquisadora: "Então, você acha que a questão do letramento eu enfoquei bem ou você acha que...", e ao complementar que "é que, às vezes, a gente tem, essa palavra é tão falada, mas assim, no geral é isso, né?" (ANA)

Perguntamos à Juliana se trabalha com a alfabetização na perspectiva do letramento. Ela respondeu que sim, dizendo que viu, na Plataforma Alfaletrar, que "a alfabetização e o letramento, eles têm que andar juntos, não tem como separar, né, o letramento da alfabetização." (JULIANA)

Juliana disse que trabalha voltada para os jogos, atividades orais, leitura de livros, cantigas e parlendas, relacionando essas atividades à importância de associar ao som e focar na alfabetização.

No depoimento de Malu, houve um silenciamento quanto às questões relacionadas ao letramento. Considerando que a docente assinalou o tema Sistema de Escrita Alfabética e Consciência Fonológica como o mais importante e Diferentes Gêneros Textuais na Alfabetização 
como o segundo menos relevante, podemos inferir que talvez haja uma valorização da alfabetização em detrimento do letramento.

Ao falar do trabalho com a literatura e a leitura deleite, perguntamos à Mariana se ela trabalhava na perspectiva do letramento. Ela respondeu que sim, a partir de algo que a criança traz para a sala de aula, como um folheto. Ressaltou a questão dos conhecimentos prévios dos alunos, afirmando ser necessário "fazer um elo de ligação com a sociedade" (MARIANA), com a função social da escrita.

Assim como a professora Ana, Mariana relaciona letramento aos conhecimentos prévios dos discentes e à oralidade. Outra questão interessante é que afirmou que algumas crianças possuem "um conhecimento de mundo muito grande, mas ela ainda não adquiriu a escrita ainda." (MARIANA) Esta fala dá a impressão de que esse conhecimento de mundo, o qual ela parece relacionar ao letramento, é adquirido fora da escola, e ela iria até esta última apenas para a aquisição da escrita, ainda que diga, em seguida, que "mas a gente tem que trabalhar paralelamente isso, não pode deixar de lado." (MARIANA)

Quando pedimos à professora para falar um pouco sobre o seu trabalho, disse que, quando os alunos chegam, o ponto de partida é a escrita espontânea, para verificar em que nível eles estão para iniciar o trabalho. Disse que trabalha com textos, parlendas, quadrinhas, textos pequenos, a partir dos quais ela faz cartazes para trabalhar a segmentação, identificação de palavras e outras propriedades do SEA. Dessa forma, a professora parece trabalhar com a alfabetização na perspectiva do letramento, mesmo que não haja tanta clareza, conforme mencionado anteriormente, na definição deste último.

Quando perguntamos à alfabetizadora Olívia se trabalhava com a questão do letramento, ela disse que não. Perguntei a ela se saberia conceituar letramento e ela disse "Eu não sei a diferença não. Assim, já ouvi, mas eu não consigo ver diferença assim...". Mais adiante, quando interrogamos a professora se ela desenvolvia alguma atividade em que trabalhava com o letramento, ela questionou: "Qual a diferença deles?” Após falarmos brevemente sobre o assunto, Olívia disse: “Ah, isso eu trabalho, então", e citou como exemplo que, "quando chega a festa junina, eu trabalho receita. A receita de pipoca, de beijinho. E costumo até trazer pra sala pra fazer junto com eles pra eles olharem a medida de cada coisa, o que que gasta." (OLÍVIA)

Uma fala que nos chamou a atenção no depoimento de Olívia, por nos dar alguns indícios da sua concepção de alfabetização e de letramento, foi quando justificou a opção pelo tema Diferentes gêneros textuais na alfabetização, como o sexto tema mais relevante, afirmando que "o seis, aí vou começar, depois de trabalhados esses níveis, ver o nível de cada aluno, aí eu vou começar a trabalhar com gênero textual. Você sabe, da palavra pra frase, da frase pro texto. Seis, né" (OLíVIA). Por meio 
desse depoimento, é possível perceber que a professora trabalha com os métodos sintéticos, e o texto só é abordado após serem trabalhadas as unidades menores, como as sílabas.

Assim, após analisar os depoimentos das professoras alfabetizadoras, percebemos que embora algumas tenham mencionado a importância de trabalhar com diferentes gêneros textuais e com o uso social destes, não conseguiram relacionar esta fala com o letramento. Além disso, algumas apresentaram dificuldade em conceituar letramento, associando-o algumas vezes a conhecimento de mundo ou a conhecimentos prévios.

Dessa forma, ainda que haja tentativas de alfabetizar no contexto de letramento, é possível perceber certa dificuldade e a priorização de uma das facetas do processo de ensino e aprendizagem da leitura e escrita: a alfabetização, embora a questão da alfabetização na perspectiva do letramento tenha estado presente entre os objetivos de seis das oito unidades dos cadernos de formação.

\section{Considerações finais}

Ao concluir este trabalho, percebemos que a participação na formação continuada no âmbito do PNAIC contribuiu com a formação das professoras alfabetizadoras, especialmente no que se refere ao Sistema de Escrita Alfabética e à Consciência Fonológica.

Três das cinco professoras apontaram ter ouvido falar da consciência fonológica pela primeira vez no PNAIC, embora já desenvolvessem algumas atividades relacionadas a ela em sua sala de aula. Assim, a participação na formação continuada teria possibilitado o conhecimento teórico de algo que já desenvolviam na prática, o que é extremamente importante, haja vista que o docente terá mais condições de desenvolver um bom trabalho à medida que compreender melhor os conceitos teóricos que subsidiam as práticas.

Além da consciência fonológica, a terceira unidade dos cadernos de formação do PNAIC contribuiu para uma maior compreensão dos níveis de conceitualização da escrita por parte das professoras. No entanto, verificamos que a maior parte das docentes encontrou certa dificuldade em descrever as atividades de intervenção que fazem para que os discentes evoluam em seus níveis de conceitualização da escrita. Nesse sentido, é fundamental destacar que, se é importante identificar em que nível de conceitualização da escrita os alunos estão, isso não é suficiente. É necessário promover situações em que os discentes possam evoluir em suas hipóteses.

Com relação ao letramento, a pesquisa demonstrou certa dificuldade por parte das professoras alfabetizadoras em conceituar e definir letramento, associando-o algumas vezes a conhecimentos prévios ou conhecimento de mundo. Além disso, foi possível perceber que, embora haja objetivos relacionados ao letramento em seis das oito unidades dos cadernos de formação, e 
algumas tentativas de alfabetizar na perspectiva do letramento, percebe-se uma priorização de uma das facetas do processo de ensino e aprendizagem da leitura e escrita: a alfabetização.

Merece destaque que o modo como as professoras, em geral, lidam com conceitos em sua prática é diferente da forma como tais conceitos são tratados na academia, em função das especificidades inerentes à prática pedagógica, haja vista que traduzem os processos linguísticos e cognitivos em métodos, procedimentos e atividades que promovam e acompanhem o desenvolvimento dos discentes diante da responsabilidade de ensiná-los a ler e escrever (SOARES, 2014). Além do mais, ressaltamos que as análises feitas ao longo deste trabalho advieram dos depoimentos das professoras

alfabetizadoras, e não da observação das suas práticas. Assim, o fato de terem encontrado dificuldade em definir o conceito de letramento e, por conseguinte, em descrever atividades em que este foi conceito foi considerado, não significa que as professoras não trabalhem com a alfabetização na perspectiva do letramento, até mesmo porque algumas docentes disseram que, embora o conceito de consciência fonológica não fosse conhecido por algumas delas, quando o conceito foi explicitado na formação, perceberam que já desenvolviam algumas atividades relacionadas à consciência fonológica em sala de aula.

Por fim, concluímos este trabalho ressaltando a importância de conhecer os conceitos embutidos no processo de ensino e aprendizagem da leitura e da escrita para o desenvolvimento de um bom trabalho, assim como a importância de alfabetizar letrando.

\begin{abstract}
:
This article is a cross-section of a broader research project whose general objective was to analyze conceptions of literacy and new literacy processes of five literacy teachers from Ouro Preto-MG, who participated in professional development within the scope of the National Elementary School Literacy Partnership (PNAIC). Through a qualitative approach, the research used documentary analysis, a questionnaire and semi-structured interviews as instruments for data collection. The data indicate that the part of the PNAIC course related to the alphabetic writing system and phonological awareness was the one that most marked the teachers and that there was some difficulty on their part in conceptualizing new literacies and in describing activities in which they were undertaken.
\end{abstract}

Keywords: Conceptions of literacy and new literacy. Continuing education of literacy teachers. Pacto Nacional pela Alfabetização na Idade Certa - PNAIC. 


\section{Referências}

AMADO, J.; FERREIRA, S. A entrevista na investigação em educação. In: AMADO, J.(Coord.) Manual de investigação qualitativa em educação. 2 ed. Imprensa da Universidade de Coimbra, 2014, p. 207-232.

BRASIL. Ministério da Educação. Secretaria de Educação Básica. Pacto Nacional pela Alfabetização na Idade Certa: a aprendizagem do sistema de escrita alfabética: ano 1: unidade 3. Brasília: MEC, SEB, 2012.

FERREIRO, E.; TEBEROSKY, A. Psicogênese da língua escrita. Porto Alegre: Artes Médicas, 1986.

MORAIS, A. G. Sistema de escrita alfabética. São Paulo: Melhoramentos, 2012.

A. G. Concepções e metodologias de alfabetização: por que é preciso ir além da discussão sobre velhos

"métodos"?

Disponível

em:

http://portal.mec.gov.br/seb/arquivos/pdf/Ensfund/alf moarisconcpmetodalf.pdf Acesso em: $5 / 2 / 2017$

SOARES, M. Alfabetização: a questão dos métodos. São Paulo: Contexto, 2016.

Letramento e alfabetização: as muitas facetas. Revista Brasileira de Educação, n. 25, Jan/Fev/Mar/Abr 2004. 